\title{
Analysis of the Educational Mechanism of College Culture
}

\author{
$\mathrm{Kai} \mathrm{Li}^{1, \mathrm{a}, ~}$, Hong $\mathrm{Li}^{2, \mathrm{~b}}$, and Hong Zheng ${ }^{3, \mathrm{c}}$ \\ ${ }^{1}$ Teaching Affairs Office, Ordnance NCO Academy Army Engineering University, Wuhan, China \\ ${ }^{2}$ School of Light-Electric and Fire-Control System, Ordnance NCO Academy Army Engineering University, \\ Wuhan, Hubei, China \\ ${ }^{3}$ City College, Wuhan University of Science and Technology, No. 1, Huangjia Bay ,Wuhan, China \\ a likaikeyan@163.com, ${ }^{\mathrm{b}}$ 442787707@qq.com, ${ }^{\mathrm{c}}$ buleeagle@qq.com \\ *Corresponding author
}

Keywords: college culture, educational mechanism, staff, coordination

\begin{abstract}
College culture is a necessary part to strengthen group cohesion, stimulate group morale and cooperate with ideological and political education. In view of some problems such as lack of force construction ideas, ignoring the campus spirit cultivation and delaying the infrastructure construction, the mechanism of college cultural education should be established and improved by following methods. First is to do three coordination between school system and campus culture system, between party committee, office and student groups, and between campus culture construction organizations. Second is to establish management mechanism, incentive mechanism and coordination mechanism. Third is to cultivate full-time staff, part-time staff and amateur cadre team.
\end{abstract}

\section{Introduction}

The word "mechanism" originated in Greek language and originally referred to the construction and operation of machines. The modern dictionary of Chinese language interprets the mechanism as action's process and mode between the organizations or parts of a working system. In social science, mechanisms are institution and methods or institutionalized methods. College culture, with its specific target and distinct group characteristics, has become a "necessity" to strengthen group cohesion, motivate group morale, and cooperate with ideological and political education to students $^{[1]}$. Therefore, it has become a concern to strengthen the research and construction of school culture education mechanism and gather consciousness of all the teachers, students and staff to participate construction of campus material culture, spiritual culture, institution culture and behaviour culture ${ }^{[2][3]}$.

\section{Existing Problems}

\subsection{Lack of Joint Efforts}

The ultimate goal of campus culture construction is to create an atmosphere to help students edify sentiment, build a healthy personality and improve quality in an all-round way. Since campus culture play an important role in realizing the target in colleges and universities. It can't be done easily by just one department' effort in school. It has relationship with many other departments. So building consensus in the aspect of educational philosophy is the primary content. However, in the process of practical construction and management, there is a narrow sense that construction of campus culture is just the student management department and the ideological education department's responsibility which become a bottleneck that cannot be easily overcome ${ }^{[4]}$.

\subsection{Ignore the Cultivation of Campus Spirit}

"Environment educate people, space educate people" already is the education creed that 
everybody knows in education circles. The competition among colleges is ultimately the competition between college culture and college brand, and the campus environment culture is an important platform for the concentrated expression of school culture and school philosophy. The construction of characteristic landscape lacks overall planning and overall design, and the situation of low-level reproduction and paying attention to the form of consciousness rather than spiritual connotation still exists. Even colleges and universities, taking the main responsibility of construction, often divides spirit cultivation and characteristics of landscape campus into two different field of work, which are in charge of by two departments respectively. This working mode makes artificial fracture between material culture and spiritual culture.

\subsection{Delay the Construction of Infrastructure}

Cultural activities and infrastructure are two important components of campus culture. The development of cultural activities is less investment, good results and students are the main force. Infrastructure investment is big, the time cycle is long, the university assumes the main responsibility. Therefore, paying attention to activities and delaying or even avoiding infrastructure construction become an obvious problem. Cultural infrastructure mainly focus on the venues and facilities such as buildings, including focusing on history of campus spirit venues, concentrating on activities of cultural activity center, focus on transmission of the campus network, etc. Cultural infrastructure is the material foundation for the development of cultural activities, is a well needs both the case and the practical work, The design of campus culture should be pay attention to the style and playing a functional role, especially the function of intensive and ease and usage for students to use ${ }^{[5]}$.

\section{The Main Causes of the Problems}

\subsection{Insufficient Understanding of the Party Committee's Project of Cultural Education}

Cultural education is a systematic project, not a comprehensive implementation of just one department but whole colleges and universities. Colleges and universities should pay attention to the importance of campus culture on school development and the important role of talent training. the cultural education construction project planning, should be combined in colleges and universities development strategy research, and taken into the whole school development planning, become the communist party will. Colleges should take the construction of campus culture as an important content of school development, and then implement into concrete work. In this respect, the colleges portal barriers between the various functional departments and responsibility category is still evident, the thought of the less trouble the better in some parts of the functional departments is still the mainstream thought.

\subsection{Insufficient Understanding of the Spiritual Culture as the Core of Education}

Spirit is the core of culture. In the name of spiritual culture, dealing with just matters of material culture is also an unsolved problem. The existence of such problems is not only related to the "gateway barrier" between the functional departments of colleges, but also to the utilitarian thought that material culture is visible and tangible and receive effect relatively easily. Compared with material culture, spiritual culture is the core of educating people, but it needs the cycles of internalization and apparent, and even may not be obvious in school in tenure of leadership. In this aspect, the idea of materializing or superficial spiritual culture during the term of the supervisor's leadership has not been eradicated due to the need of performance statistics.

\subsection{Insufficient Understanding of the Need for Real Respect of the Student Body}

At present, the colleges take the principal position of students is primarily to mobilize, inspire and rely on. Detailed said is fully arouse the enthusiasm of students to participate in activities, giving a certain degree of spirit and material incentives, depending on the students, especially students backbone to complete all activities in all aspects of the construction of campus culture, especially the cultural activities. However, this is only the starting point for students to play the 
main role. Respect is the deepest attitude to recognize students' subjectivity. Respect should include trust and perspective-taking, which is to avoid arranging what students do but actually to serve what students want to do. In this aspect, the traces of paternalism in colleges are still obvious.

\section{Solutions and Advices}

\subsection{Good Coordination among Different Departments}

To establish the system of the construction of campus culture idea, construction of campus culture system including the party committee, administrative system and mass group should be established and improved. Good coordination mechanism about construction of campus culture should be established and executed. And on this basis, three coordination following should be done well.

\subsubsection{Coordination between the University System and the Campus Culture Operation System.}

The construction of campus culture should be coordinated with the focus of school work and the social environment so as to give full play to the positive role of education in ideology and politics.

\subsubsection{Coordination among the Party Committee, the Administration and the Mass Organizations.}

Every department and every member of the campus culture construction system should have a clear understanding and active participation in colleges cultural activities objectives, principles and policies making. As a subordinate organization, information on campus cultural activities should be collected in a timely manner and fed back to the leading authorities of the school in order to make corresponding decisions.

\subsubsection{Coordination among the Campus Cultural Construction Organization Small System Internal.}

Campus culture construction of each system function is associated with the function of each part to play. Each part is just the different division of labor, and should support each other, strengthen mutual cooperation and avoid mutual shuffle and wrangling.

\subsection{Establish Three Mechanisms}

A scientific and effective mechanism is an important guarantee for the construction of campus culture. The construction of campus culture should be an organic whole rather than a loose mechanical combination. Through the establishment of an efficient operation mechanism, the respective forces of colleges and universities can be combined organically to form a joint force, so as to give full play to the educational efficiency of campus cultural construction.

\subsubsection{Establish a Management Mechanism.}

Strengthening the leadership of the party and government on campus culture is the key to the establishment and prosperity of campus culture. The establishment of necessary scientific management institutions is the basic condition for the construction of campus culture. The leading group of cultural construction is set up under the leadership of the party committee of colleges, and the leading group of cultural construction is directly responsible to the leading group of cultural construction. Cultural construction leading group is responsible for guiding, checking and promoting the construction of college culture, taking the culture construction in the development of college overall planning, setting campus culture construction's plan, content, and methods. The office of cultural construction carries out systematic and long-term management of cultural construction by establishing scientific and practical rules and systems.

\subsubsection{Establish an Incentive Mechanism.}

Colleges should provide financial support for the construction of campus culture, including hardware construction in the planning of campus infrastructure construction projects for special construction, software construction and cultural activities construction in the school budget. Special fund can be set up to carry out comparison on construction of campus culture for every year. 
Recognition ceremony can be held to praise the individual and unit or project which performed very well in the culture construction, and give them material and spiritual rewards. Special funds for scientific research on campus cultural construction should be set up to encourage all teachers and students to conduct beneficial theoretical research and discussion on campus cultural construction and for cultural activities of campus cultural construction. A moderate amount of funds should be invested for school-level activities, and appropriate support should be given to the special cultural activities of all units ${ }^{[6]}$.

\subsubsection{Establish a Cooperative Mechanism.}

Developing the cultural construction project implementation plan, and setting the target task, head unit, cooperation unit, time schedule in document for the university spirit construction, cultural brand construction, cultural activities construction, culture carrier construction, cultural media construction, etc. By this way we can take construction of campus culture of many branches and orderly organic integration into a systematic whole and take each department into the school authority responsibility system, clear their responsibility division of labor and mutual relationship.

\subsection{Establish Three Teams}

Culture key staff, as the school culture activity's main force, spreading advanced ideas, participating in the activities of organization culture, promoting innovation theory, carrying forward the advanced culture, are an important force in ideological politics education. Therefore, it is necessary to absorb the backbone of education in ideological and political affairs and build a highquality campus cultural construction team combining professional and part-time jobs.

\subsubsection{Establish a High-quality Campus Cultural Construction Full-time Team.}

This team mainly consists of the college youth league cadres, propaganda department cadres, each department) political work cadres and counsellor etc, They can participate in part of decision making, organization and coordination and have the broad field of vision, strong ability and high sense of responsibility and dedication consciousness. We should introduce protective policies for them, give sufficient preparation, and implement relevant treatment. So that this team can focus on their own work for the construction of campus culture.

\subsubsection{Establish a High-quality Campus Cultural Construction Part-time Team.}

This team mainly consists of two parts: the backbone of teachers and the backbone of students, who can participate in the specific implementation of cultural education construction at a certain level. They have high work enthusiasm and excellent professional quality. We should not only give full play to their enthusiasm in work, but also help them solve difficulties in activities. We should not only focus on improving their ideological and moral quality, but also strive to improve their literary and artistic ability and organizational ability. We should support them in making contributions to the school and care for their own development.

\subsubsection{Establish a High-quality Campus Culture Construction Amateur Backbone Team.}

The team mainly consists of students with different art special features. We need to give full play to their potential. We should not only maintain the team's staff relatively stable, but also pay attention to discovering and developing new members to ensure the team sustainable and living; we should also pay attention to training and improving their cultural and artistic quality, and give full play to the leading role of student activists.

\section{References}

[1] Ma Laihuan. "Cultural value orientation on campus". Beijing: Beijing University of technology press, 2012.

[2] Li Weisheng. "New ideas of school cultural construction": initiative generation. Beijing: Beijing normal university press, 2012. 
[3] Zhang Yu. Thoughts on the co-construction of ideological and political theory teaching in colleges and universities and campus culture [J]. Contemporary education BBS, 2010, (7).

[4] Zhou Yibin. Research on University Culture Crisis in Current China [D]. Shanghai:East China Normal University,

[5] Research of Higher Vocational College's Internal Governance from the Perspective of University Culture [J]. Management Observer.2017 (35).

[6] Tian Lianjin. Functional Orientation and Construction Operational Mechanism of University Culture [J]. Tribune of Social Sciences.2015, (7). 